\title{
Evaluation of Morphological and Biochemical Characteristics of Sorghum [Sorghum bicolor [L.] Moench] Varieties in Response Salinity Stress
}

\author{
Wilton Mbinda $^{1^{*}}$ and Musa Kimtai ${ }^{1}$ \\ ${ }^{1}$ Department of Biochemistry and Biotechnology, Pwani University, Kilifi, Kenya.
}

Authors' contributions

This work was carried out in collaboration between both authors. Author WM designed the study, supervised the study, conducted some experiments, performed the statistical analysis and wrote the first manuscript. Author MK conducted some experiments and analyzed all. Both authors agreed on the final appearance of the manuscript after careful review.

Article Information

DOI: 10.9734/ARRB/2019/v33i130110

Editor(s):

(1) Dr. Amit Kesarwani, Assistant Professor, Department of Agronomy, College of Agriculture, G. B. Pant University of Agriculture \& Technology, India. (2) Dr. Gabriel Oladele Awe, Department of Soil Resources \& Environmental Management, Faculty of Agricultural Sciences, Ekiti State University, Nigeria. (3) Paola Angelini, Department of Applied Biology, University of Perugia, Perugia, Italy. Reviewers:

(1) Jalal "Ahmad Said" Al-Tabbal, Applied University, Jordan. (2) Henrique Kuhn Massot Padilha, University Federal of Pelotas, Brazil. (3) Benjawan Chutichudet, Mahasarakham University, Thailand Complete Peer review History: http://www.sdiarticle3.com/review-history/50834

Original Research Article

Received 01 July 2019

Accepted 03 September 2019

Published 10 September 2019

\begin{abstract}
Salinity is among the most severe and widespread environmental constrains to global crop production, especially in arid and semi-arid climates and negatively affecting productivity of salt sensitive crop species. Breeding and selection of salt tolerant crop varieties is therefore necessary for sustainable plant productivity. Given that germination and seeding phases are the most critical phase in the plant life cycle, this study aimed to evaluate seed germination potential and associated traits under salt stress conditions as a simple approach to identify salt tolerant sorghum varieties [Gadam, Sc Sila and Serena] which are adaptated to various agroecological regions. Salinity stress was applied by addition of $\mathrm{NaCl}$ at three different levels of stress [100, 200 and $300 \mathrm{mM} \mathrm{NaCl}$, while plants irrigated with water were used as control. Evaluation of tolerance was performed on the basis of germination percentage, shoot and seed water absorbance, shoot and root length, leave water content, seedling total chlorophyll content and morphologic abnormality. Our results showed that salinity stress significantly impacts all features associated with germination and early development
\end{abstract}

*Corresponding author: E-mail: wilton.mbinda@gmail.com; 
of seedlings. Our results indicated that salinity stress substantially affects all traits associated with germination and early seedling growth, with the effect of salinity being dependent on the variety used and level of salinity stress applied. Among the tested sorghum varieties, Gadam was established to the most salt tolerant variety, suggesting its potential use for cultivation under salinity stress conditions as well as its suitability for use as germplasm material in future sorghum breeding programmes. For a greater insight into comprehensive mechanisms of salinity tolerance in sorghum, we suggest further research on genomic and molecular analysis.

Keywords: Chlorophyll content; salinity stress; salt tolerance; sorghum; relative water content.

\section{INTRODUCTION}

Salinity stress is a major constrain that affect crop growth and metabolism, resulting to severe damage and a loss of productivity primarily in arid and semi-arid regions [1]. Exposure to salinity stress triggers a variety of biochemical and physiological responses in plants and these responses include chlorophyll degradation, reduction in water content as well as morphological changes [2].

The challenging aim of breeding for enhanced yield under salinity stress, is certainly dependent on existing selection methodologies and robust screening of salt-tolerant sorghum germplasm. Due to complex inheritance of traits coupled with wide variations in environmental conditions, the applied screening methods are time-consuming and inefficient. Hence, it is essential to define selection criteria to be employed for identification of tolerant varieties. Because of this, seed germination potential under salt stress has demonstrated to be a reliable tool for estimation of genetic tolerance [3]. This strategy allows the selection of more salt tolerant plant varieties at early development phases, therefore allowing for greater cost-effectiveness and time-efficient e of all subsequent breeding activities. This research aimed to determine the potential for seed germination of three sorghum varieties subjected to different concentrations of salinity stress. Germination is one of the most critical periods for a crop subjected to salinity. Higher salt stress retards seed germination and root emergence and leads to poor crop establishment which is deleterious and prevents the plant in maintaining their proper nutritional requirements necessary for their healthy growth [2]. Reduced germination is the consequence of either direct toxic effect of salt or the general delay of the germination process caused by osmotic stress [4].

Sorghum [Sorghum bicolor [L.] Moench] is an essential staple food crop is primarily cultivated in Asia and Africa for food but it is an ingredient for the livestock and biofuel industry in the developed countries [5]. Sorghum is largely grown in marginal lands commonly found in semi-arid arid regions where soil salinity is excessively high for optimal growth, development and production, and groundwater with high salts content is predominantly the primary source of water. Hence, screening for salt-tolerant crop varieties and enhancing the salinity tolerance for susceptible crops in salt-inflicted soils are very essential. The ability of sorghum to be productive under harsh conditions with minimal inputs, make it a model crop for crop improvement for utilization of marginal lands in order to meet food demands which is expected to increase in the near future due to growing world population $[6,7]$. Even through sorghum is considered to some extent tolerant to salinity [5], it is exposed to great deal of salt stress due to increased irrigation which is worsened by poor drainage and climate change [Zhu, 2007]. Although differential responses on morphology, physiology and biochemistry of sorghum genotypes under salinity stress have been documented $[8,9,10]$, there is no specific information pertinent to the sorghum varieties grown in Kenya. This study was therefore designed to analyze the morphological and biochemical parameters of three sorghum varieties grown in different ecological zones in Kenya under $\mathrm{NaCl}$-induced salinity and germination rate, seedling growth and morphology, relative water content and leaf total chlorophyll content of the selected sorghum varieties were investigated.

\section{MATERIALS AND METHODS}

\subsection{Plant Growth and Stress Treatment}

Seeds of three sorghum varieties [Gadam, Sc Sila and Serena] provided by the Kenya Seed Company, Nairobi, Kenya were used as plant material. The study was conducted in greenhouse at Pwani University, Kilifi, Kenya. The varieties' responses to salinity stress at germination and seedling growth period have not been established. Healthy seeds were sorted by handpicking before washing them 
with distilled water to remove dust and other particles. Ten seeds were sown to a depth of approximately $1 \mathrm{~cm}$ in plastic pots that had been filled with about $5 \mathrm{~g}$ of sterile sand soil and plugged with glass-wool facilitated drainage. For analysis of sorghum varieties for gemination rate, the seeds were subjected to two different treatments viz control with $50 \mathrm{ml}$ double distilled water and with different concentrations of $50 \mathrm{ml} \mathrm{NaCl}$ [100, 200 and $300 \mathrm{mM}$ ] at an interval of 3 days for two weeks. Observations on the rate of germination were recorded on the $17^{\text {th }}$ day of treatment. Seeds were considered to have germinated when the radicle was at approximately $2 \mathrm{~mm}$ long. The experiment was repeated three times with five replications for each treatment.

\subsection{Growth Conditions upon Salinity Treatment}

Germinated sorghum seeds were grown for two weeks under greenhouse conditions. To find out the salt effects on growth of sorghum seedlings, the seedlings were subjected to osmotic stress by irrigating with $50 \mathrm{ml}$ of different concentrations $\mathrm{NaCl}$ [100, 200 and $300 \mathrm{mM} \mathrm{NaCl}$ for 21 days at an interval of 3 days while the control pots were watered with distilled water. Three replications were used for each set of treatment. After treatment, three plants from each treatment were sampled at random and the growth of the plants studied by recording the shoot length and root length.

\subsection{Relative Water Content Estimation}

One leaflet from the first fully expanded leaf of three plants per variety and per treatment was cut from a plant on the $21^{\text {st }}$ day. Immediately after cutting, the leaflet was weighed to obtain the fresh weight [FW]. Thereafter, the leaflet was immersed in double distilled water and incubated under room temperature $\left[25^{\circ} \mathrm{C}\right]$ for 4 hours. Afterwards, the leaflet was taken out, thoroughly wiped to remove the water on the blade surface and its weight measured to obtain turgid weight [TW]. The leaflet was dried in an oven for 48 hours and its dry weight [DW] measured. The relative water content [RWC \%] was calculated using the formula: RWC $=[[F W-D W] /[T W-$ DW]] $\times 100$.

\subsection{Determination of Total Chlorophyll Content}

To determine the chlorophyll amount, fresh leaves $[0.2 \mathrm{~g}]$ of leaves plants were crushed in
$80 \%$ acetone. Grinding was done by vortexing several times to remove chlorophyll efficiently. The extract was centrifuged at $5000 \mathrm{~g}$ for 3 minutes. The absorbance of the obtained supernatants was measured at 646 and $663 \mathrm{~nm}$. The total chlorophyll content in each sample, expressed in mg g-1 [FM], was calculated using the following formula: $T C=20.2\left[A_{646}\right]+8.02\left[A_{663}\right]$ $\times \mathrm{V} / 1000 \times \mathrm{W}$ where $\mathrm{V}$ corresponds to the volume of total extract per liter and $W$ is the mass of the fresh material [11].

\subsection{Statistical Analysis}

Completely randomized design was used in the study and the experiments were performed in triples with five biological replications. Data were analysed with Minitab statistical software version 19 and comparison between means was done using Fisher's least significant difference test. Differences were considered significant at confidence coefficient of $p<0.05$ and the means were written as \pm standard deviation [SE]. The graphs were plotted with SigmaPlot 11.0.

\section{RESULTS}

\subsection{Effects of Salt Stress on Seed Germination}

The effect of $\mathrm{NaCl}$ stress on sorghum seeds germination, evaluated by the percentage of germinated seeds after 17 days, is as shown in Fig. 1. The results showed that for all sorghum varieties, the germination rate decreased with an increase of the $\mathrm{NaCl}$ concentration. However, the negative effect of $\mathrm{NaCl}$ stress differed according to the varieties. Under untrested conditions, all three sorghum varieties had statistically different germination rates ranging from $74.68 \%$ for Gadam to $75.13 \%$ for Serena [Fig. 2]. Under 100 $\mathrm{mM} \mathrm{NaCl}$ treatment, Gadam recorded a higher germination rate of $4546 \%$ as compared to Sc Sila [43.61\%] and Serana [34.62\%]. For plants growing under severe osmotic pressure of 300 $\mathrm{mM} \mathrm{NaCl}$, only $14.31 \%$ germination rate was recorded from Gadam, while Serena and Sc Sila recorded $6.93 \%$ and $2.66 \%$ respectively [Fig. 2].

\subsection{Effect of $\mathrm{NaCl}$ on Seedlings Growth}

Analysis revealed statistically significant differences in root and shoot length among varieties and treatments [Fig. 1]. Although the increased concentrations of $\mathrm{NaCl}$ resulted in a significant reduction of both root and shoot length, these tissue types responded differently under salinity stress [Table 1 and Table 2]. 
Specifically, there was a reduction in length at $\mathrm{NaCl}$ concentrations of $100 \mathrm{mM}$ for roots and shoots, respectively. However, root length did not provide an accurate estimate for the classification of varieties with respect to tolerance as the length across the varieties under similar $\mathrm{NaCl}$ treatments were similar [Table 2]. In relation to shoot length, Gadam was the best performing variety, whereas Serena and Sc Sila had poor growth of shoots when grown with 300 $\mathrm{mM} \mathrm{NaCl}$ [Table 1]. At control conditions, the sorghum varieties had similar height. Similar results were also reported for root development under control and treatment conditions [Table 2]. Despite the drastic effects on seedling elongation, no morphological deformities were observed, indicating that salinity stress does not result to the development of abnormal phenotypes.

\subsection{Effects of Salt Stress on Relative Water Content}

Analysis of variance showed that salinity stress had a significant effect on the leaf relative water content of the finger millet seedlings [Fig. 1]. As expected, in the plants under control conditions showed significantly high relative water content compared to the salt stressed ones [Fig. 1]. Plants grown under moderate water stress treatment of $100 \mathrm{mM} \mathrm{NaCl}$ demonstrated the highest variation of relative water content values. In contrast, the three varieties irrigated with $300 \mathrm{mM} \mathrm{NaCl}$ had a significantly reduced relative water content, compared to the control plants. At this concentration, very small shoots formed all varieties Sc Sila and Serena, resulting in the lowest water content.
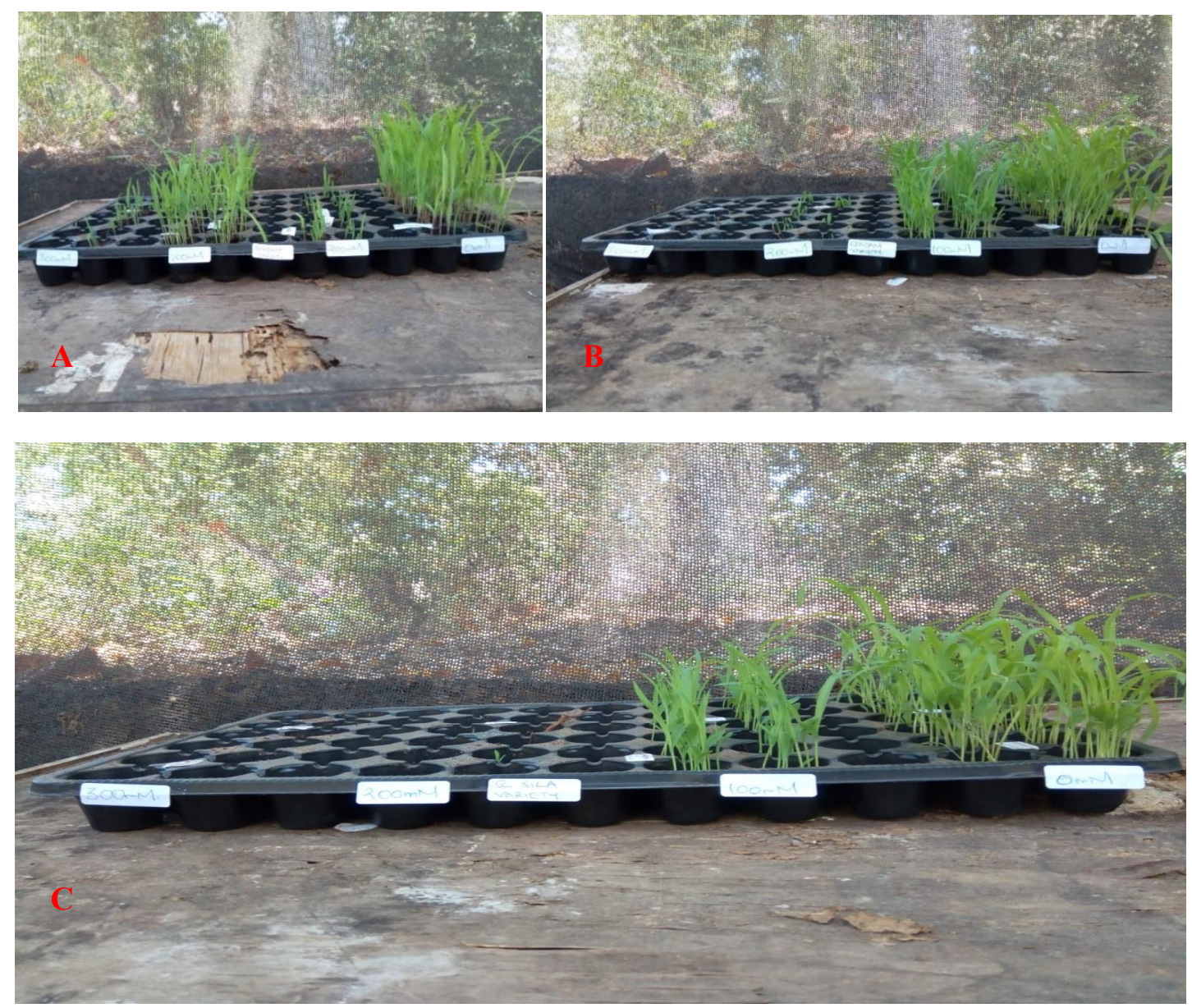

Fig. 1. Effects of salinity stress upon germination of sorghum varieties. A. Serena, B. Gadam and C. Sc Sila 


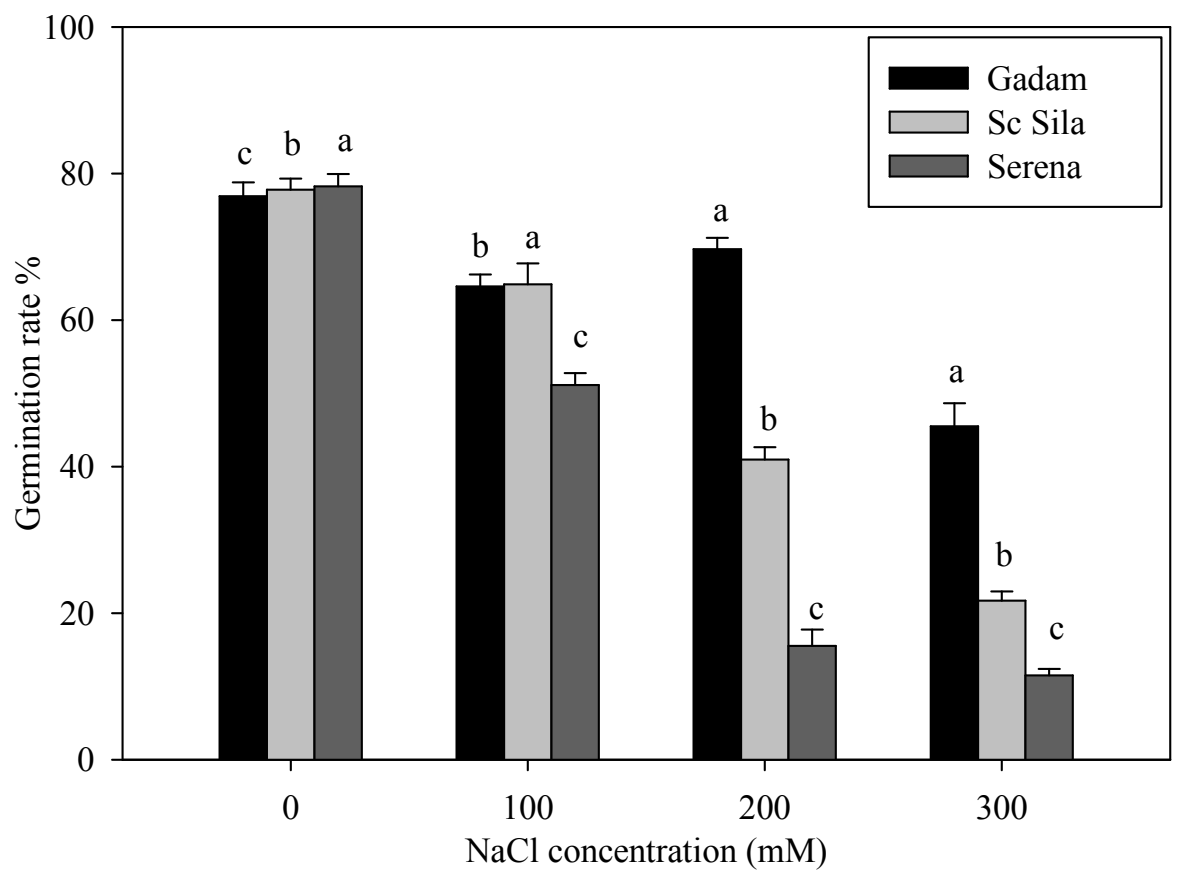

Fig. 2. Effects on salinity stress on germination of sorghum seeds (Bars with the same letters do not differed at 5 or $1 \%$ level of probability)

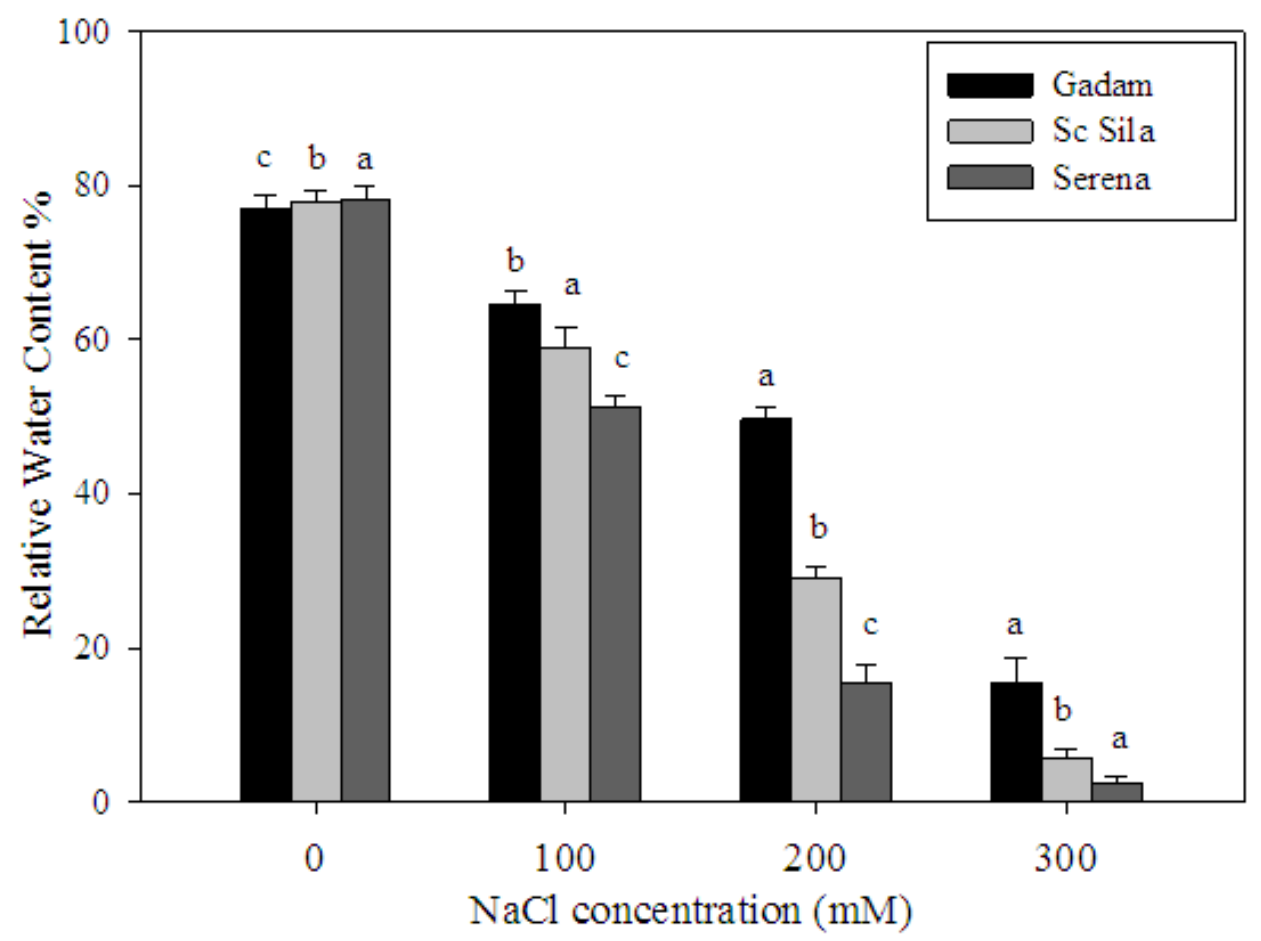

Fig. 3. Effect of salt stress on leaf relative water content (Bars with the same letters do not differed at 5 or $1 \%$ level of probability) 


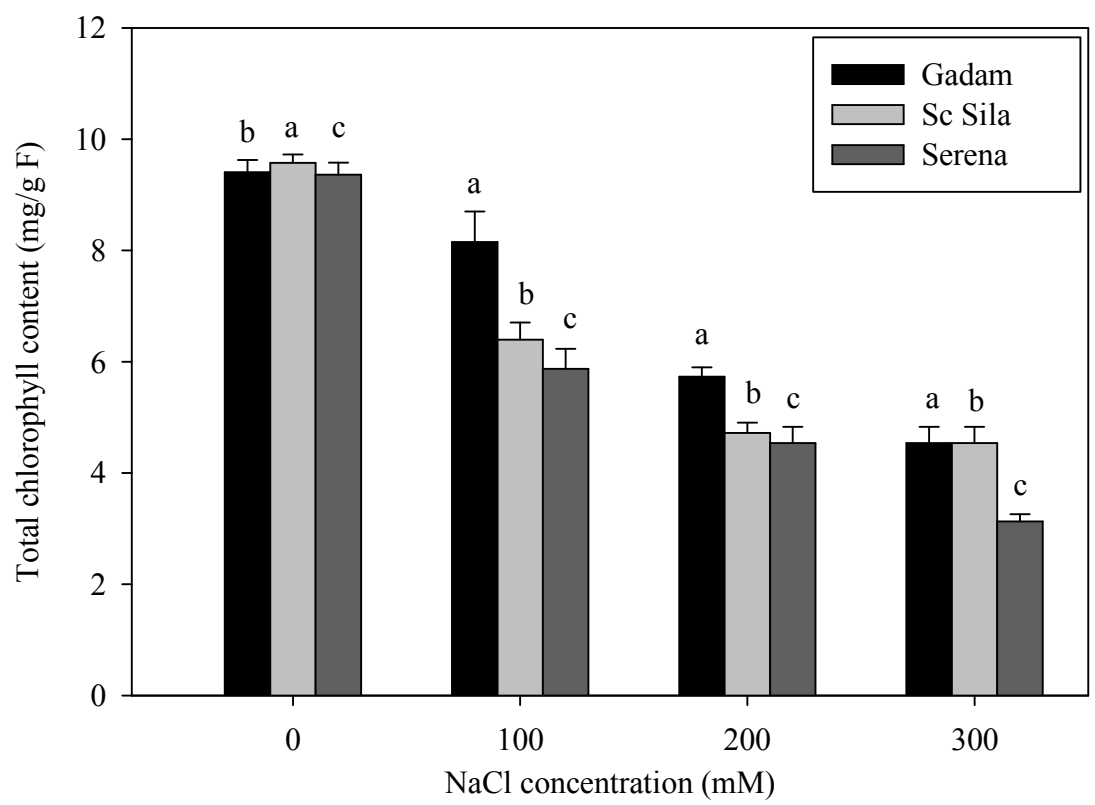

Fig. 4. Effects of salt stress on total chlorophyll content (Bars with the same letters do not differed at 5 or $1 \%$ level of probability)

Table 1. Effect of $\mathrm{NaCl}$ concentrations on shoot height of different varieties of sorghum seedlings

\begin{tabular}{lllll}
\hline Variety & \multicolumn{4}{c}{$\mathbf{N a C l}$ concentration [mM] } \\
\cline { 2 - 5 } & $\mathbf{0}$ & $\mathbf{1 0 0}$ & $\mathbf{2 0 0}$ & $\mathbf{3 0 0}$ \\
\hline Gadam & $6.02 \pm 0.55^{\mathrm{a}}$ & $5.11 \pm 0.41^{\mathrm{a}}$ & $4.2 \pm 0.08^{\mathrm{a}}$ & $3.25 \pm 0.07^{\mathrm{a}}$ \\
Sc Sila & $6.15 \pm 0.76^{\mathrm{a}}$ & $4.6 \pm 0.3 \mathrm{a}^{\mathrm{b}}$ & $2.69 \pm 0.59^{\mathrm{b}}$ & $2.17 \pm 0.49^{\mathrm{b}}$ \\
Serena & $6.58 \pm 0.61^{\mathrm{a}}$ & $4.29 \pm 0.1^{\mathrm{b}}$ & $1.79 \pm 0.57^{\mathrm{b}}$ & $1.56 \pm 0.35^{\mathrm{b}}$ \\
\hline
\end{tabular}

For each sorghum $\mathrm{NaCl}$ treatment, values within a column sharing same letter comparing $\mathrm{NaCl}$ treatments are not significantly different at $p<0.05$ [Fishers LSD]. Each value represented as mean \pm SE [standard deviation] are the mean of three replications

\subsection{Effects of Salt Stress on Total Chlorophyll Content}

Results from Fig. 4 shows an inverse relationship between $\mathrm{NaCl}$ induced salinity stress responses and total chlorophyll content values for all sorghum varieties tested. Differences for chlorophyll content values were also observed among varieties. At the beginning of the experiment, total chlorophyll content across the varieties was similar ranging from 9.37 to 9.44 $\mathrm{mg} / \mathrm{g} \mathrm{FW}$. Imposition of moderate salinity stress conditions of $100 \mathrm{mM} \mathrm{NaCl}$ caused a slight decrease of chlorophyll content which ranged from $5.8730 \mathrm{mg} / \mathrm{g}$ FW for Serena to $8.15 \mathrm{mg} / \mathrm{g}$ FW for Gadam. In severe salt stress conditions of $100 \mathrm{mM} \mathrm{NaCl}$, significant decrease of total chlorophyll content was also observed among the three varieties with Gadam having the highest $[4.54 \mathrm{mg} / \mathrm{g} \mathrm{FW}$ ], while Serena had the least $[3.13 \mathrm{mg} / \mathrm{g} \mathrm{FW}$. Among the varieties exposed to severe salt stress, varieties Gadam retained relatively high chlorophyll content when compared with Sc Sila and Serena.

\section{DISCUSSION}

Salinity stress is one of the most serious adverse factors that affect growth and productivity of saltsensitive plant species, including sorghum $[12,13]$. Increased irrigation and the predicted climate change are expected to increase the severity and frequency of soil salinization, especially in arid and semi-arid areas where cultivation of sorghum occurs. Developing varieties with improved salinity tolerance will 
therefore help in sustaining increased productivity under agricultural areas that are prone to salinity stress.

Our findings reveal that salinity stress influences significantly all sorghum characteristics associated with germination and early seedling development, with salinity tolerance depending on the stress level of the selected varieties. Nevertheless, the varieties responded differently to the varying concentrations of salinity. As regards germination, these variations were linked to the proportion of final germination as well as the rate of germination. Our findings are comparable with those of other research which show that salinity stress acts as an inhibitor by stopping germination, without loss of viability at high stress levels, and by delaying germination at concentrations where the process is not completely avoided $[14,15,16]$. Salt stress affects seed germination mainly by reducing the soil solution's osmotic potential to delay seed water absorption, causing embryo toxicity to sodium and/or chloride, or changing protein synthesis. Again, poor seedling emergence might be caused by hypocotyls mortality associated with the salt accumulation at the soil surface [17]. Even though germination rate of all varieties was considerably altered by high level of salinity stress, the most severe effects were recorded in genotype Serena and Sc Sila, whereas Gadam had the best performance with regard to this trait. Our results also revealed that increasing salinity stress concentrations progressively reduced development of seedling, expressed as decreased lengths of root and that the salt effect depended on salinity level and variety. As anticipated, these length decreases were the greatest at the highest salinity levels and most probably mirror the toxic effects combined with insufficient water uptake and nutrients $[18,19]$. Furthermore, there was significant variation in reduced length between organs and between varieties. The shoot and root lengths were differentially affected by salinity stress, with roots being more seriously affected even under low $\mathrm{NaCl}$ concentrations. The observed effects of salinity stress on roots could be attributed to the to the direct exposure salinity, and possibly more cellular concentrations of $\mathrm{Na}^{+}$and $\mathrm{Cl}^{-}$, therefore causing more harm than in the shoots. We hypothesized that Gadam could perform satisfactorily in soils with less severe salinity.

An essential strategy for plant tolerance to $\mathrm{NaCl}$ stress is the ability to retain high water status during salinity stress. Decrease in relative water content as in response to salinity stress has been reported in a wide variety of plants $[20,21]$. This variation in the capacity of plants to hold water can be ascribed to their differential capacity to absorb water from the soil by creating a reduced potential gradient of water from the soil and also because of the distinction in the capacity of the plant varieties to adjust and maintain osmotic turgor in the tissues. The differences in relative water content in all varieties observed in our study could be correlated with their different ability of water absorption from soil. The decline in relative water content recorded was a main factor that caused decreased growth responding to osmotic stress in the sorghum plants. Under salt stress, Sc Sila and Serena varieties were more affected by the decrease in relative water content than Gadam. This suggested that the three sorghum varieties had different sensitivity when subjected $\mathrm{NaCl}$ induced salt stress. The increased water retention capability found in the Gadam could play a crucial part in crop's survival under salinity stress.

Chlorophyll content strongly depends on the species' physiological responses and their ability to tolerate stress [22]. Measurement of chlorophyll content is one of the most effective indicators for salinity tolerance identification of sorghum [23]. In our study, salinity stress caused an increase in total chlorophyll content in the

Table 2. Effect of $\mathrm{NaCl}$ concentrations on root length of different varieties of sorghum seedlings

\begin{tabular}{lllll}
\hline Variety & \multicolumn{4}{c}{$\mathrm{NaCl}$ concentration [mM] } \\
\cline { 2 - 5 } & $\mathbf{0}$ & $\mathbf{1 0 0}$ & $\mathbf{2 0 0}$ & $\mathbf{3 0 0}$ \\
\hline Gadam & $4.97 \pm 0.61^{\mathrm{a}}$ & $3.92 \pm 0.60^{\mathrm{a}}$ & $2.70 \pm 0.47^{\mathrm{a}}$ & $1.79 \pm 0.38^{\mathrm{a}}$ \\
Sc Sila & $4.92 \pm 0.35^{\mathrm{a}}$ & $3.85 \pm 0.25^{\mathrm{a}}$ & $2.38 \pm 0.24^{\mathrm{a}}$ & $1.59 \pm 0.22^{\mathrm{a}}$ \\
Serena & $4.92 \pm 0.18^{\mathrm{a}}$ & $3.90 \pm 0.19^{\mathrm{a}}$ & $2.28 \pm 0.20^{\mathrm{a}}$ & $1.45 \pm 0.11^{\mathrm{a}}$ \\
\hline
\end{tabular}

For each sorghum $\mathrm{NaCl}$ treatment, values within a column sharing same letter comparing $\mathrm{NaCl}$ treatments are not significantly different at $p<0.05$ [Fishers $L S D$ ]. Each value represented as mean $\pm S E$ are the mean of three replications 
leaves of all sorghum varieties although the decrease was differed in terms of variety and the stress level. These observations explained why the total chlorophyll content of all decreased under salinity stress. The decrease in total chlorophyll content could be due the accumulation of $\mathrm{Na}^{+}$and $\mathrm{Cl}^{-}$ions and possibly the reduction of $\mathrm{K}^{+}$which hinders the process of chlorophyll synthesis by influencing the activity of some enzymes containing $\mathrm{Fe}^{3+}$. Besides this, the decrease in chlorophyll contents might be related to an increase of chlorophyll degradation or a decrease of chlorophyll synthesis [22,24].

\section{CONCLUSION}

In conclusion, our study findings confirm that sorghum's tolerance to salinity stress is highly variety-dependent, as manifested by differentiation in terms of germination and early seedling development under salinity stress. In addition, our findings point to the existence of large genetic variation for this specific trait among the different sorghum varieties. Given the need to identify new sources of salt tolerance, the observed varietal variation indicates that a larger number of sorghum varieties should be considered in future research. Our findings underline that variability in the stress response may be readily explored during the germination phase and early seeding development, for reliable selection of salt-tolerant genotypes at early growth stages. Finally, the findings indicate Gadam's supremacy in tolerating salinity stress, thus suggesting the possibility for its cultivation under salt stress conditions as well as its suitability for use as germplasm material in future sorghum breeding programmes.

\section{ACKNOWLEDGEMENT}

The authors thank Pwani University for providing materials, reagents and lab space to conduct this study.

\section{COMPETING INTERESTS}

Authors have declared that no competing interests exist.

\section{REFERENCES}

1. Vaidyanathan $H$, Sivakumar $P$, Chakrabarty R, Thomas G. Scavenging of reactive oxygen species in $\mathrm{NaCl}$-stressed rice [Oryza sativa L.]-differential response in salt-tolerant and sensitive varieties. Plant Science. 2003;165(6):1411-1418.
Available:http://dx.doi.org/10.1016/j.plantsc i.2003.08.005

2. Acosta MJ, Ortuño $M$, Bernal-Vicente $A$, Diaz-Vivancos P, Sanchez BM, Hernandez J. Plant responses to salt stress: Adaptive mechanisms. Agronomy. 2017;7(1):4-38.

DOI: 10.3390/agronomy7010018

3. Hanumantha RB, Nair RM, Nayyar H. Salinity and high temperature tolerance in mungbean [Vigna radiata [L.] Wilczek] from a physiological perspective. Frontiers in Plant Science. 2016;7:957.

DOI: 10.3389/fpls.2016.00957

4. Debez A, Belghith I, Pich A, Taamalli W, Abdelly C, Braun HP. High salinity impacts germination of the halophyte Cakile maritima but primes seeds for rapid germination upon stress release. Physiologia Plantarum. 2018;164(2):134144.

DOI: $10.1111 / p p l .12679$

5. McLaren JS, Lakey N, Osborne J. Sorghum as a bioresources platform for future renewable resources. In Proceedings $57^{\text {th }}$ Corn and Sorghum Research Conference. CD ROM. American Seed Trade Association. Alexandria, VA, USA; 2003.

6. Igartua E, Gracia MP, Lasa JM. Field responses of grain sorghum to a salinity gradient. Field Crops Research. 1995;42(1):15-25.

DOI: 10.1016/0378-4290[95]00018-L

7. Ramirez VJ, Jarvis $A$, Läderach $P$. Empirical approaches for assessing impacts of climate change on agriculture: The EcoCrop model and a case study with grain sorghum. Agricultural and Forest Meteorology. 2013;170:67-78.

DOI: 10.1016/j.agrformet.2011.09.005

8. Bibi A, Sadaqat HA, Tahir MHN, Akram HM. Screening of sorghum [Sorghum bicolor Var Moench] for drought tolerance at seedling stage in polyethylene glycol. Journal of Animal and Plant Sciences. 2012;22:671-678.

9. Niu G, Rodriguez DS. Responses of growth and ion uptake of four rose rootstocks to chloride-or sulfate-dominated salinity. Journal of the American Society for Horticultural Science. 2008;33:663669.

10. Amzallag GN, Lerner HR, Poljakoff MA. Induction of increased salt tolerance in Sorghum bicolor by $\mathrm{NaCl}$ pretreatment. Journal of Experimental Botany. 1990;41: 29-34. 
Available:https://doi.org/10.1093/jxb/41.1.2 9

11. Maswada HF, Djanaguiraman M, Prasad PVV. Seed treatment with nano-iron [III] oxide enhances germination, seeding growth and salinity tolerance of sorghum. Journal of Agronomy and Crop Science. 2018;4(6):577-587.

DOI: $10.1111 /$ jac. 12280

12. Arnon DI. Copper enzymes in isolated chloroplasts. Polyphenoloxidase in Beta vulgaris. Plant Physiology. 1949;24(1):115.

13. De La Rosa-lbarra M, Maiti RK. Biochemical mechanism in glossy sorghum lines for resistance to salinity stress. Journal of Plant Physiology. 1995;146(4): 515-519.

14. Mukami A, Ngetich A, Mweu C, Oduor RO, Muthangya $M$, Mbinda WM. Differential characterization of physiological and biochemical responses during drought stress in finger millet varieties. Physiology and Molecular Biology of Plants. 2019;26(4):837-846.

DOI: $10.1101 / 603944$

15. Khayamim S, Rouzbeh F, Poustini K, Sadeghian SY, Abbasi Z, Afshari RT. Seed germination, plant establishment, and yield of sugar beet genotypes under salinity stress. Journal of Agriculture, Science and Technology. 2018;16:779-790.

16. Bajji M, Kinet JM, Lutts S. Osmotic and ionic effects of $\mathrm{NaCl}$ on germination, early seedling growth, and ion content of Atriplex halimus [Chenopodiaceae]. Canadian Journal of Botany. 2002;80(3):297-304.

DOI: 10.1139/B02-008

17. Dias LS, Dias AS, Pereira IP. Ionic effects of $\mathrm{NaCl}$ counter osmotic inhibition of germination and seedling growth of Scorzonera hispanica and subsequent plantlet growth is not affected by salt. Botany. 2015;93(8):485-496.

DOI: $10.1139 / c j b-2015-0015$
18. Ouji A, El-Bok S, Mouelhi M, Younes MB, Kharrat M. Effect of salinity stress on germination of five Tunisian lentil [Lens culinaris L.] genotypes. European Scientific Journal. 2015;11(21):1857-1870.

19. Majid A, Mohsen S, Mandana A, Saeid JH, Ezatollah E, Fariborz S. The effects of different levels of salinity and indole-3acetic acid [IAA] on early growth and germination of wheat seedling. Journal of Stress Physiology \& Biochemistry. 2013;9(4):329-338.

20. Nxele $X$, Klein A, Ndimba BK. Drought and salinity stress alters ROS accumulation, water retention, and osmolyte content in sorghum plants. South African Journal of Botany. 2017;108:261-266.

DOI: 10.1016/j.sajb.2016.11.003

21. Silva ED, Ribeiro RV, Ferreira-Silva SL, Viégas RA, Silveira JAG. Comparative effects of salinity and water stress on photosynthesis, water relations and growth of Jatropha curcas plants. Journal of Arid Environments. 2010;74(10):1130-1137.

DOI: 10.1016/j.jaridenv.2010.05.036

22. Chaves MM, Flexas J, Pinheiro C. Photosynthesis under drought and salt stress: Regulation mechanisms from whole plant to cell. Annals of Botany. 2009;103(4):551-560.

DOI: $10.1093 / a o b / m c n 125$

23. Romero L, Belakbir A, Ragala L, Ruiz JM. Response of plant yield and leaf pigments to saline conditions: Effectiveness of different rootstocks in melon plants [Cucumis melo L.]. Soil Science and Plant Nutrition. 1997;43[4]:855-862.

DOI: $10.1080 / 00380768.1997 .10414652$

24. Kalaji HM, Jajoo A, Oukarroum A, Brestic M, Zivcak M, Samborska IA, Ladle RJ. Chlorophyll a fluorescence as a tool to monitor physiological status of plants under abiotic stress conditions. Acta Physiologiae Plantarum. 2016;38(4):102113.

(c) 2019 Mbinda and Kimtai; This is an Open Access article distributed under the terms of the Creative Commons Attribution License (http://creativecommons.org/licenses/by/4.0), which permits unrestricted use, distribution, and reproduction in any medium, provided the original work is properly cited.

Peer-review history:

The peer review history for this paper can be accessed here: http://www.sdiarticle3.com/review-history/50834 